\title{
Function first or form first-a comparison of two design methods for undergraduate basic course
}

\author{
Xie Guanyi ${ }^{1}$, Duan Huifang ${ }^{1}$ \\ ${ }^{1}$ South China University of Technology, Guangzhou,China
}

\begin{abstract}
Talking about form and function in the architecture, two major traditions in design are always inevitable. They are two methods of architectural design: the first one is used by Beaux-Art system which takes form and order as the core; the second one is of Bauhuas system which focuses on function. Architecture is closely related to the interior, so are there also two design methods in the field of interior design? Through analysis of interior design textbooks in different academies, it was found that most existing design methods are based on function. Function-based design methods have a series of operable standard methods for function, but also have the problem of high level of functional logic and low level of formal logic. Does interior design also have a design approach starting from form and order and unifying function logic and formal logic? By transplanting the "kit-of-parts approach" in architectural design into interior design, applying the two design methods in undergraduate course of environmental design and comparing the two course design results, it was verified in this paper which design method is easier to balance form and function in basic design course.
\end{abstract}

\section{Function and form : two traditions of architectural design}

By the turn of the 19th and 20th centuries, Beaux-Arts "composition method" represented by the École Supérieure Libre d'art de Paris had formed a clear subject system. Beaux-Arts system initially focused on the concept of disposition proposed by Durand in the early 19th century. By the early 20th century, Julien Guadet, a teacher of the École Supérieure Libre d'art de Paris, presented the concept "element of composition", since when composition replaced disposition as a core issue in design. To put it simply, composition is to deal with the relations among volume, space and elevation based on the principle of axial symmetry, and the design mainly focuses on how to deal with the relations among the three and integrate them into a whole1. The plan is the first and foremost thing in Beaux-Arts system, for section and elevation both come from it. It presents the formal order, functional distribution and architectural structure of building and it is safe to say that the plan is the generator of Beaux-Arts architecture and the core of Beaux-Arts design, so what Beaux-Arts system advocate is a form-based design method.

The great emphasis Beaux-Arts architecture laid on form and technique had inevitably resulted in less consideration of factors like structure, material, environment and climate and led to the tendency to separate from practice. Then in the ideological trend of modernism Bauhuas education system was born. In its early stage Bauhuas focused on space contents in elementary training, but later functionalist design method became dominant in modern architectural design and teaching. It stressed the analysis of facts and the decisive roles of external factors and use functions in architectural modeling. Students were asked to discover the needs in field research, so that they could learn to pay attention to social, technical and economic issues, etc., associated with architecture. This is a function-based design method.

However in actual work, the function-based design method, without a clear guideline for formal space, has its one-sidedness, just as American scholar Herdeg termed the late stage of Bauhaus "decorative diagram", namely an architectural design process of "generating an architectural diagram according to objective functional analysis and then overlaying a series of abstract decorations on it". Then in 1950, Texas Educational Reform put forward the teaching idea of "kit-of-parts approach" which matched modern architecture, and used this approach to cope with Bauhaus' formal logical weakness in its later stage.

\section{Function-first design method}

Back to interior design, standard design method usually takes three steps: 1 . list the functions required by the venue, put the functions in the plan reasonably so that it presents a reasonable functional logic. 2. Consider the streamline of space and arrange them in space reasonably. 3. Generate the perspective while considering the spatial image3. The spatial image here means the orders of 
facade and style instead of the order of spatial form. These design steps suggest the function-based design method. This design method can be confirmed in the Principles of Interior Design by Mr. Lai Zengxiang in Tongji University and the Modern Interior Design Course by Zhu Chun in China Academy of Art. Taking the example of the design method summarized by Zheng Shuyang in Tsinghua University in his Interior Design Process, we can see that function-first design takes these basic steps: 1. List the functions required by the venue and then study and partition them. Its feasibility is shown by a functional diagram with abstract logic. 2. Adjust the functions: for each determined function draw a circle on the plan, then try and make comparison repeatedly to grasp and adjust their interrelations on the whole. 3. Draw the plan and the perspective: standardize the reasonable functions and put them in the plan, then generate space perspective according to the logic of the plan while considering the spatial image.

The function-based design method has an apparently rational spirit and economic efficiency. The functional analysis process is also easy to be imparted as it is describable. However, overstress on function tends to reduce plane layout to a result of functional needs and traffic analysis but lack formal contents. When function is the sole indicator of architectural space, the close relationship between plane layout and spatial form is overlooked, and the way of transformation from spatial function to spatial form is cut off. So, the problem with this design method is its weakness in formal logic for it lacks a method for spatial form transformation. Taking the example of an entry for Asian Design Award designed by a group of students for a theme experience museum. From its analysis diagram we knew its design steps: 1 . Partition the functions required by the museum, such as Winter Olympics VR experience zone, cafe, etc. 2. Arrange the functions reasonably in the plan. 3. Transform the plan to perspective.

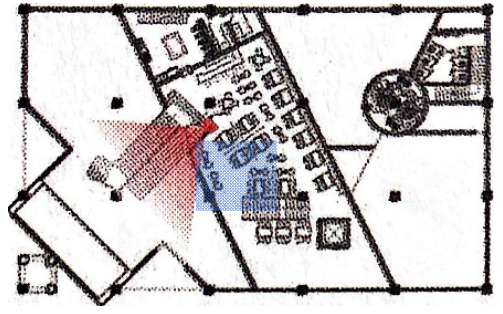

Figure 1 Picture from Asian Design Award

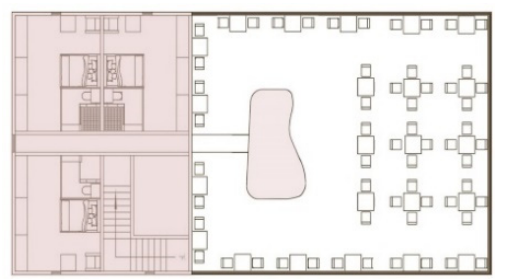

Figure 2 Picture from student's environmental design work of South China University of Technology

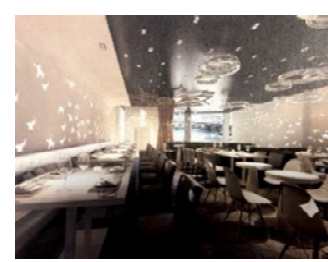

Figure 3 Picture from Asian Design Award
The above analysis clearly shows that it is hard to combine function and form in the course design. What is prevailing in interior design is the function-first design method. This design method is quite mature in terms of functional logic, but its problem is the lack of effective means to transform functional logic into formal logic when pushing functional analysis to spatial form. This echoes the problem with Bauhaus' function-orientated design method in its later stage. Therefore, we transplanted the "kit-of-parts approach" from architectural
The plan of the cafe in this case shows that the designer first expressed the cafe's functional needs, then used furniture to divide the reception and seating areas and put seats reasonably in the plan. In this plan you can see an irregular-shaped block, but you cannot tell its purpose, because it also represents the seating area (Figure 1). Such negligence of spatial form makes the plan difficult to understand. A good piece of work should organization and arrangement of planar functions. For example, the plan in Figure 2 shows a multi-functional space which combines residence and cafe. Before putting expressed the order of the space. By putting bedroom in the left large block, coffee making and selling areas in the middle small block and the open seating area in small blocks around the cafe, the designer created a large-to-small, primary-to-secondary formal logical sequence in the plan. Such design not only ensures the spatial function but also take formal logic into account, making the plan easier to understand.

Back to the plan in Figure 1, after it was arranged reasonably, the designer used it to generate the perspective (Figure 3). In order to highlight the theme "snowflake", the designer used concrete shapes of snowflake on large areas of ceiling and wall, making the integrity of space broken by the shape of snowflake. And to enrich the space, the designer designed columns into the shape of tree and used different sizes of lights on ceiling and various furnishings in the space. These steps in this case finally completed the design, but there are two problems: 1 . The plan is simply focused on function and streamline, the purposes of its formal logic contents cannot be understood by readers. 2 . In the perspective, the designer focused more on spatial image, e.g. the shape of object or the style and theme of space, than on spatial form, which leads to a disconnection between function and form. combine functional logic and formal logic very well by specific functions in the plan, the designer roughly

design into the interior design and tried to solve the contradiction between function and form in undergraduate basic course using form-first design method. A comparative research was conducted on the applications of the two design methods in undergraduate interior design course. There is no denying that the form-first design method is a reflection and test on the existing teaching materials. 


\section{Application and comparison of two design methods in teaching}

Firstly, from the point of design steps, the currently prevailing function-based design method takes the following steps: a. Investigate the site, observe and discover micro phenomena, for example, graffiti on wall or sundries piled in corner, etc., and use them as the medium for functional analysis. b. Analyze and dissect the special phenomena discovered and find out the root causes, summarize the fundamental problems with the site and form functional logic. For example, the graffiti reflects a problem of logistics management or space utilization. c. Reorganize the spatial functions and traffic sequence according to functional logic, and use designed modules to express solid model (Figure 4). d. The expression of spatial image. Function-first work method is a process to find problem, analyze problem and solve problem by functional organization. By contrast, form-first design includes these steps: a. Design the spatial volume and type. Choose from bungalow, building or high-rise building according to the given dimension $6 \mathrm{~m} \times 12 \mathrm{~m} \times 14 \mathrm{~m}$. After determining the volume, choose two different spatial types as the theme for design, such as the combination of office and residence. $b$. Design the formal elements and spatial order, choose one abstract element language from poles, sheets and blocks for spatial organization. c. Use model to scrutinize and study the spatial form; $d$. put in the functions and use model to scrutinize the unity of form and function. Form-first work method is mainly a process from the conception of spatial formal order to the transformation of spatial form and function.

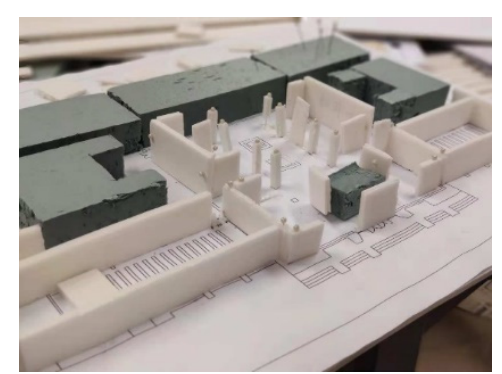

Figure 4 Picture from coursework of 2017 environmental design class of South China University of Technology
Secondly, from the perspective of the designing result, a function-based design of an exhibition hall by students was analyzed. It was inferred in research that the essential space problem was unreasonable space utilization of existing exhibition hall and switching of functions. To switch among different functions, the designer placed mobile display racks in the space to form different functions by different combinations of racks (Figure 5) and generate the perspective after reasonable arrangements. The designer tried to enrich the space by adding materials and textures on the facade or putting all kinds of furniture in the plan (Figure 6). As a contrast, a form-based design of office and clothing functions was also analyzed. The designer chose the volume of bungalow according to the given dimension and used poles as the main abstract element. The main focus was the study on spatial form. First, abstract elements were used to limit two states of space. Black blocks were used as enclosed space and the rest as open space (Figure 7). Then the functional bubble chart (Figure 8) summarized in research was placed in the two corresponding spatial states; fitting room, warehouse and toilet which require privacy were placed in black blocks; exhibition areas were placed in semi-open space enclosed by poles. These poles form a continuous texture in the whole space and become related to the banister, windows and even walls. Through the operation and organization of different elements the whole process achieved the diversity of spatial forms (Figure 9). By shaping the formal order in the plan, an apprehensible spatial order was presented, and by organizing the poles and room blocks in clothing exhibition area, sparse and dense spatial relationships and the horizontal formal order were presented. If you look around the space, it will change with your sight and give you rich spatial experience (Figure 9), so as to coordinate the form and the function.

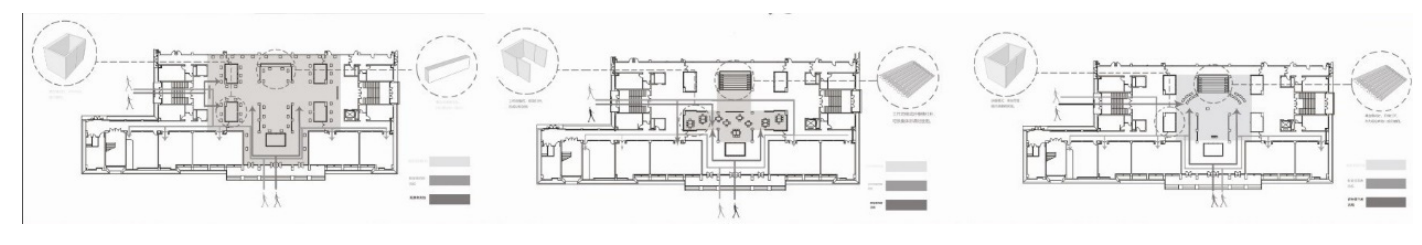

Figure 5 Picture from coursework of 2017 environmental design class of South China University of Technology 


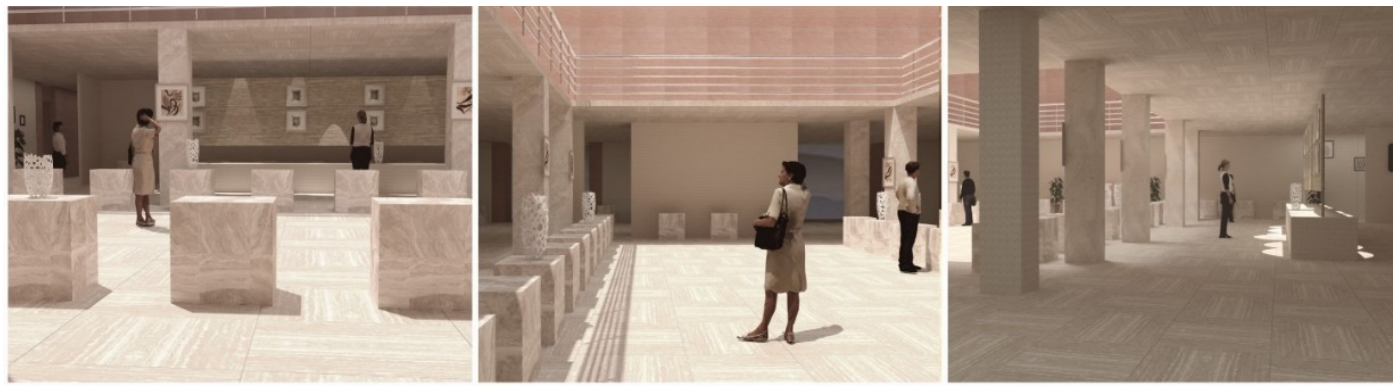

Figure 6 Picture from coursework of 2017 environmental design class of South China University of Technology

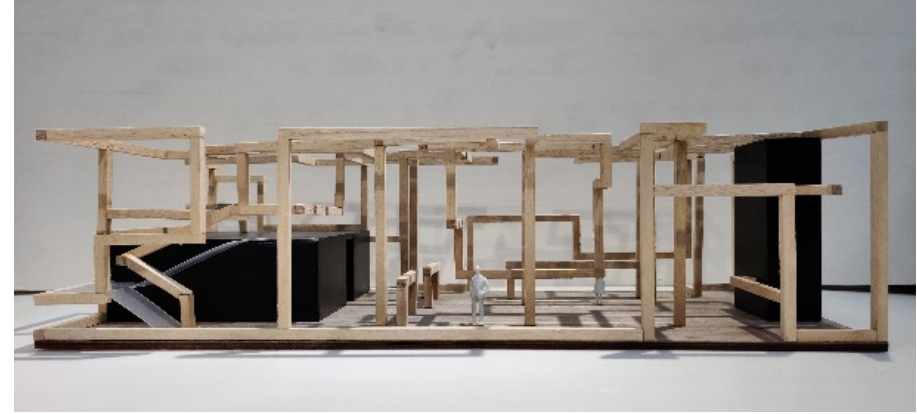

Figure 7 Picture from coursework of 2018 environmental design class of South China University of Technology

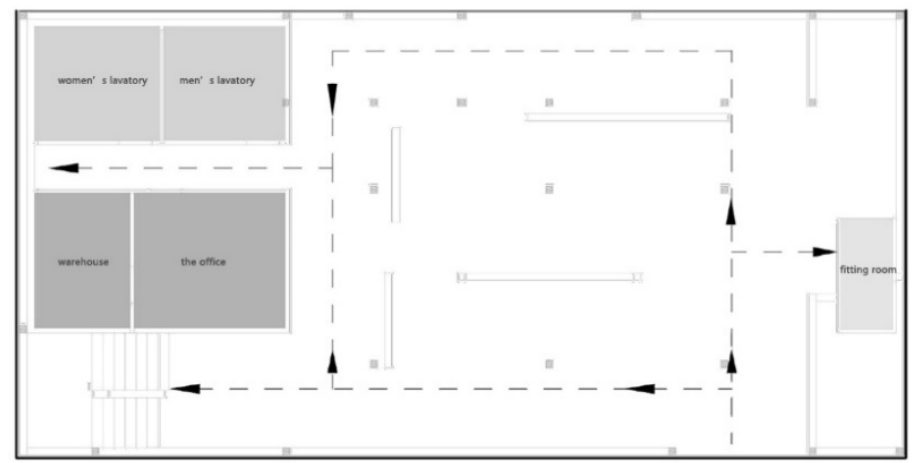

Figure 9 Picture from coursework of 2018 environmental design class of South China University of Technology

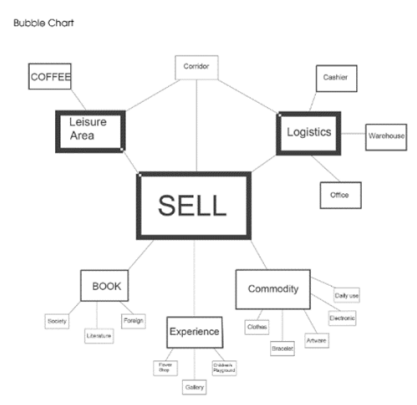

Figure 8 Picture from coursework of 2018 environmental design class of South China University of Technology
Thirdly, in terms of the evaluation of the designing result, the principles to evaluate function-based design include: a. The clarity of field research logic determines the accuracy of the problem with the site; b. Rational unity of functional organization and streamline planning. The evaluation of form-based design follows two principles: a. The clarity of operation determines the clarity of space and formal language expression; $b$. The unity of simple operation and rich spatial experience.

Finally, as to the tool of layout expression, function-based expression uses computer to generate perspectives of scrutinized space from different angles, while form-based expression uses photos of each space to present the effect. When using computer to record and express space perspective, students will enrich the space by adding furniture and ornaments, but when using pictures taken with camera, they could examine the model with their eyes and thus focus on the spatial state and form more intuitively.

\section{Conclusion}

Advantages and disadvantages:

Advantages of function-first design: through a series of steps from discovering phenomenon to finding the cause and inducing the problem, it exercises and stimulates the students' logical thinking as well as inductive and organizational abilities; students have a degree of certainty about reasonable arrangement of the functions. Disadvantage: when a reasonable plan is transformed into perspective, no spatial form for perception could be deduced. Typically the designer will try to enrich the space by adding materials and textures on the facade or putting all kinds of furniture in the plan, but factors like the senses of dimension, enclosure and rhythm, etc., that determine the spatial form cannot be 
brought into full play with function-first design method, and this in turn leads to a disconnection between function and form.

Advantages of form-first design: with designed volume and spatial state, the focus is put on space issues inside the volume rather than changes of the volume itself. It gets rid of superficial application of "style" and goes deep into the root of space creation. By shaping the formal order in the plan and implanting functions, it gives the plan strong spatial relationships. Just as professor Wang Fangji of Tongji University wrote in his paper The Entanglement between Abstract Order and Practical Confinements, once the expression inside space is highlighted, the space is no longer a structure that exists to perform certain functions in a binary state, but an object to be experienced by people in space-time4, while the spatial experience of the corresponding perspective is accordingly enriched. Perhaps this design method is better in combining form and function. Disadvantage: function and structure are relatively weakened.

Difficulties: the function-first method has difficulties in two aspects: 1. The research stage; 2. The students found it difficult to tease out a clear logic from phenomenon to problem. The difficulty of form-first method lied in the stage of function intervention. When functions intervened in the space, it was difficult to find a balance between the two and then scrutinized form was destroyed with the intervention of function., so it was difficult to connect up existing functions and the formal logic of space in order to achieve an ideal spatial state.

\section{Conclusion}

Form and function are equally important for design. The ultimate goal should be a good combination of both regardless of which one to start with. We tried to transplant the kit-of-parts approach as the space training theme of interior design, in order to achieve a relative balance between function and form in undergraduate interior design course. Although this design method is not well applied in teaching yet, it is not necessarily a bad attempt, just as the case with Louis Kahn whose work made him exceed the dominant empty functionalism in America thanks to his new understanding of the form. The attempt to apply the form-based design in the design method of undergraduate course is a reflection and test on existing teaching materials, and also an effort to solve the problems existing in present interior design. It might be a direction worth considering for design teaching.

\section{References}

1. Gu Daqing: Learn from Beaux-Arts-Modern Interpretation of Traditional Architectural Design Teaching Method, Architectural Journal, August 2018

2. Architect Zeng Yin: From Harvard Bauhaus to the Texas Rangers: the Legacy of Colin Rowe I, 2015.
3. Zheng Shuyang: Interior Design Process [M], Department of Environmental Art Design, Academy of Arts \& Design, Tsinghua University, China Architecture \& Building Press, 61-71, 210-218.

4. Wang Fangji: The Entanglement between Abstract Order and Practical Confinements - on the Design Method of Qingpu Youth Activity Center, Architectural Journal.

5. Zhu Chun, Zhou Xintao: Modern Interior Design Course [M], China Academy of Art Press, 109-112

6. Lu Zhenwei, Lai Zengxiang: Principles of Interior Design [M], China Architecture \& Building Press, Chapters 2 and 3.

7. Gu Daqing, Bai Tingwei: Space, Construction and Design [M], China Architecture \& Building Press, $18-20$

8. Zhu Lei: Spatial Operation [M]. Southeast University Press. 29-31

9. Tong Ming: Beaux-Arts and modern architecture: about the Breaking and Continuation of Two Traditions [J]. Time Architecture. 2018.

10. Tian Xuezhe, Yu Jingzhi, Guo Xun, Lu Xiangdong: Form Construction Studies [M]. Tsinghua University, China Architecture \& Building Press, 12-17

11. Peter Eisenman: The Formal Basis of Modern Architecture, 1953. P25

12. Zeng Yin: From Harvard Bauhaus to the Texas Rangers: the Legacy of Colin Rowe I (J), 2015.

13. Louis Kahn: The Idea of Order, China Architecture \& Building Press, 2006 